Proceedings of the 2011 Winter Simulation Conference

S. Jain, R.R. Creasey, J. Himmelspach, K.P. White, and M. Fu, eds.

\title{
COMPLEX SYSTEMS MODELING FOR SUPPLY AND DEMAND IN HEALTH AND SOCIAL CARE
}

\author{
Sally Brailsford \\ Eric Silverman \\ Stuart Rossiter \\ Jakub Bijak \\ Richard Shaw \\ Joe Viana \\ Jason Noble \\ Sophia Efstathiou \\ Athina Vlachantoni \\ University of Southampton \\ Southampton SO17 1BJ, UK
}

\begin{abstract}
This paper introduces a major new cross-disciplinary research project that looks at the UK health and social care system, as part of an ambitious, broader initiative to apply methods from complexity science to a range of key global challenges. This particular project aims to develop new, integrated models for the supply and demand of both health and social care, in the context of the societal change brought about by migration, mobility and the ageing population. We discuss the background to the work, and the broad way in which we intend to leverage complexity science. This is made more specific with a brief discussion on existing demographic models, and some examples of model-building in progress. We conclude with a glimpse into the subtly difficult problems of fostering such innovative interdisciplinarity.
\end{abstract}

\section{INTRODUCTION}

'Complexity science' and 'complex systems modeling' are terms which have grabbed the public attention since the rise to prominence of the Santa Fe Institute in the 1990s. Like chaos theory - which enjoyed a similar popularity in the 1980s, exemplified by the best-selling book by Gleick (1987) — and building on many of its ideas, complexity science has grown in popularity because of its applicability to prominent topics such as climate change, evolution and social networks. Complexity science as a whole encompasses a range of mathematical and computational modeling approaches which deal with complicated systems, where the word complicated is used in its everyday sense but the term system has a special meaning, with its roots in cybernetics and the general systems theory of von Bertalanffy (1968). A system is an object which consists of a number of inter-related and interconnected component parts, and whose overall behavior and/or properties cannot be deterministically predicted merely by aggregating or averaging all the individual constituent parts. This leads to 'emergent' behavior or properties exhibited by the system as a whole and not by any individual component part. Take for example this line of dots: ......... We may reasonably claim that no individual dot has the property of length, but an arrangement of dots in a systematic, linear way does.

Complexity science has found a variety of applications. Quantitative modeling methods from a variety of disciplines (including mathematics, statistical mechanics and computer science) have been applied to a range of problems in neuroscience, biology, medicine, engineering, networks and environmental science. Emergent properties of systems have also been studied using a range of operations research 


\section{Brailsford, Silverman, Rossiter, Bijak, Shaw, Viana, Noble, Efstathiou and Vlachantoni}

modeling and simulation approaches, including agent-based modeling and system dynamics (Brailsford 2008).

To date, most of these applications have been in the natural sciences. However, many human or social systems are clearly also highly complex, and exhibit emergent behavior - for example, a crowd of people at a political demonstration may behave in a totally different way from that in which the lawabiding individuals who form the crowd would each normally behave. In 2009, the UK Engineering and Physical Sciences Research Council decided to fund a program called "Complexity Science for the Real World", whose ambitious aims are to "develop and apply the tools and techniques of complexity science for tackling major societal research challenges" (CSRW 2010). Four major UK research projects were funded under this program, all with the intention of bringing these aims to fruition. The project described in this paper, the Care Life Cycle project (CLC 2010), is a five year program at the University of Southampton. The CLC began in October 2010 and is concerned with both complexity science and traditional methods to issues of supply and demand for health and social care in a changing and ageing society. The project is led by Professor Jane Falkingham from Southampton's School of Social Sciences. The team contains 13 further academic co-investigators, five post-doctoral research staff, and a total of about $8 \mathrm{PhD}$ students - with coverage across a wide range of disciplines: agent-based modeling (complexity science), demography, gerontology, operations research, and social statistics.

\section{THE RESEARCH CONTEXT}

The UK's population is ageing. In 2001, there were 9.3 million people aged 65 and over, comprising $16 \%$ of the total UK population; by 2031 this figure is projected to rise to 15.8 million, representing $22 \%$ of the total population (Office for National Statistics 2008). Older people are the major users of health and social care services. At the same time as increasing the demand for health and social care services, population ageing is affecting the supply of health and social care professionals as the health workforce grows, diversifies, and ages. The efficient organization of the UK's care services in order to cope with these trends represents a major challenge that is critical to the UK's prosperity and quality of life.

In the UK, health care is funded centrally by taxation and is provided to patients free of charge at the point of delivery by the National Health Service (NHS). However, social care is means-tested and is provided by the local authority where the person lives. Thus, people who require assistance with everyday tasks (such as cooking, bathing, shopping and cleaning) in order to live independently (e.g., the frail elderly, and disabled or vulnerable adults) may have to pay for this themselves, depending on their financial circumstances. The operations research modeling literature contains a vast number of models for the demand and the supply of health care services, although these models have mainly focused on specific conditions (and in some cases on specific locations). However there have been relatively few models for demand or supply of social care, and none to date which address supply and demand of both, despite the close connection between health and social care (especially in the older population).

Population ageing is only one factor in a complex set of issues influencing both the supply of and demand for health and social care. First, demand is not simply a function of age but also of need, which in turn is influenced by a wide range of factors, including changes in the profile of disability and disease, the development of new technologies, and changes in levels of income and wealth (Segal and Bolton 2009). Similarly, the supply of the formal workforce is influenced by both demographic trends and economic factors, particularly the level of wages relative to other sectors, as well as the policy environment on education, training places and workplace retention. The migration of health-care workers from developing countries has significantly increased in recent years (Stilwell et al. 2004) and this in turn has implications for future demand as these health care workers from diverse ethnic backgrounds themselves age. The overwhelming majority of social care is provided by family members, most notably co-residential partners and adult children. Current policy recognizes this role and explicitly relies upon its continuance (Department of Health 2008a). However, trends in family formation and dissolution along with greater female labor force participation and increased geographical mobility, both of older parents and adult 
children, point to a change in the availability of family care for older people (Evandrou and Falkingham 2004).

These challenges in forecasting the future health workforce have been highlighted by economists such as Maynard (2006) and reiterated in the review of workforce planning conducted by the Warwick Institute for Employment Research (Bosworth, Wilson, and Baldauf 2007). A number of commentators have called for a full dynamic systems approach allowing for inter-reactions and feedbacks (Joyce et al. 2004), and the need to move beyond traditional supply-based planning was further recognized in the recent Department of Health Review on the NHS workforce (Department of Health 2008b).

\section{MODELING APPROACH}

In this project, we aim to bridge the gap between our disciplines and, at the same time, develop a suite of models which provide insight at several levels into the interactions between the various parts of this hugely complex system. We do not intend to build a monolithic mega-model of the entire UK population: such a brute-force approach of developing a massive, highly detailed individual-based model until believable outputs emerge at the macro level is not considered viable. We are committed to dealing with models on multiple scales and levels of resolution because we believe that this is the way science works: the identification of intermediate-level explanatory structures is what makes a real complex system intelligible to policy-makers and to other scientists (Di Paolo, Noble, and Bullock 2000). We see the project as providing an environment in which fledgling models can be compared, contrasted, and integrated. Tensions between models are informative but, ultimately, unsuccessful or inconsistent models will be discarded; effective ones will be retained, further developed, and used to cross-validate the inputs or outputs of other models pitched at different levels of detail. One primary contribution to complexity science tools and techniques will therefore be in the area of model integration. Here we can make progress on the urgent question of how models using complexity science techniques (e.g., agent-based modeling, cellular automata, etc.) can best be related to and integrated with each other, and with results from empirical work, traditional statistical models, and more established modeling techniques such as game theory, discrete-event simulation and system dynamics. (Gilbert and Troitzsch (2005) provide a comprehensive summary of potential social simulation approaches.)

However, while critically important, achieving working integrated models of the relevant socioeconomic systems solves only half of the problem. The challenge that remains is to develop and encourage much more sophisticated ways of carrying this science forward to inform policy. The CLC team is committed to working with policy-makers and care planners/providers in order to develop models which are of practical use in the real world. To ensure that the research questions are well-defined, and the CLC models relevant, engagement will occur throughout the project with both local and national health and social care organizations, and is already underway with the UK's Department for Health, Centre for Workforce Intelligence and Hampshire County Council.

\section{MODELING IN DEMOGRAPHY}

Since demography is most closely associated with studying population changes, which are of key interest to this project, understanding current modeling approaches in this area is critical to positioning our research. Contemporary demography is facing major challenges, especially with respect to the limits of predictability of future population developments, as well as the ability to combine information about micro- and macro-level processes, whilst finding a compromise between the complexity and simplicity of analytical tools. This section discusses these issues in more detail.

Traditionally, demography was - and largely still is - highly reliant on quantitative data describing the populations of concern. The ultimate aim of a demographic analysis has often been related to predicting future population size and structure, and responding in this way to real-life questions related to public policy and planning. Hence, among the tools of demography there are many methods stemming from two main traditions: deterministic models of population dynamics, as well as methods of mathematical statis- 
tics. The first group, firmly rooted in algebra and calculus, inform how populations would change under various assumptions underlying the demographic rates and other indicators, which can be directly derived from data. Examples of such tools include Lotka's model of population dynamics, cohort-component models, multiregional models and multistate models (for a historical overview, see, e.g., Jóźwiak (1992)). The second group of demographic methods, based on probability theory and its applications, extend the analysis to the questions of estimation and prediction of unknown past or future quantities, and their uncertainty. Here, the methodology encompasses such tools as survey-based inference, regression models, hazard models, extrapolations based on time series, and similar (see Alho and Spencer 2005). Clearly, the two can, and often are, interlinked, as for example, when demographic rates are calculated based on survey data, or when a cohort-component model is equipped with time-series-based predictions of particular components of demographic change (fertility, mortality and migration).

Nevertheless, with respect to the possibility of answering some of its traditional research questions, demography seems to be reaching its limits. Even though the age structure of the population already carries important information about the future, which renders populations more predictable than for example macroeconomic indicators, there are still clear boundaries with respect to predictability of future population size and composition (Keyfitz 1981). This is due to uncertainty being embedded in particular components of population change: fertility, mortality and migration. All of them can be seen at the same time as the result of a variety of both macro-level (social) and micro-level (individual) processes. In recent years, there were a few attempts to build multi-level models that would bridge the gap. Such models usually allow for an analysis of population broken down into several states - for example: age, marital status, occupation, state of health. The models are usually based on probabilities of transition between various states, estimated from the available data, which enable the modeler to simulate individual life courses (trajectories) and subsequently aggregate them in order to obtain the macro-level picture of the whole population.

One notable attempt to link the micro- and macro-level in demography is the MicMac project, which was undertaken by the Netherlands Interdisciplinary Demographic Institute - NIDI (Willekens 2005; Zinn et al. 2009). The project aimed to develop new population forecasting techniques based upon the life course perspective, bridging the gap between macro-level demographic forecasts and micro-level factors which may affect larger-scale demographic trends. Consequently, the MicMac software package attempts to address this challenge by integrating a top-level macrosimulation - Mac — into the dynamic microsimulation core - Mic (Zinn et al. 2009). Both components of MicMac generate projections based on transitions between demographic states, but Mac generates cohort biographies while Mic generates individual biographies.

In microsimulation approaches, built upon the pioneering work of Orcutt (1957), the behavior of the basic unit is modeled rather than simply examining aggregate behavior. In the case of MicMac, the central unit of analysis is the individual life course. This kind of micro-macro link, drawn from the use of multistate models in certain applications to labor market dynamics in economics, allows for a more complete picture of population dynamics and demographic change than either method taken individually, and also ensures coherence of aggregation between the micro and macro levels (see also Courgeau 2007).

However, the practical utility of multistate, and in particular multi-level models, can be limited by their potentially very high data demands, which can explode as the dimension of the state space increases. Besides, it can be argued that such models as MicMac do not fully take into account and integrate all sources of uncertainty surrounding demographic processes at both levels of analysis. Transition probabilities serve to generate individual-level randomness, but they themselves are largely uncertain, as are various other parameters of the models. Both limitations seem to be stemming from the same source: a strong focus on empirical data, without which the models cannot produce meaningful predictions.

However, as Epstein points out, such an emphasis on empirical data and quantitative prediction is not the only way that the modeling enterprise can proceed: 
"On this point, many non-modelers, and indeed many modelers, harbor a naïve inductivism that might be paraphrased as follows: 'Science proceeds from observation, and then models are constructed to 'account for' the data.' The social science rendition - with which I am most familiar - would be that one first collects lots of data and then runs regressions on it. This can be very productive, but it is not the rule in science, where theory often precedes data collection." (Epstein 2008; §1.1)

Thus, modeling need not be focused predominately on prediction. Instead, illuminating underlying processes or providing an element of explanation of some problem or behavior is often an equally valid goal, one which the agent-based approach often adopts.

More generally in social simulation, there is a tension between complexity and simplicity when constructing models. For example, Edmonds and Moss (2005) explicitly define KIDS (Keep It Descriptive, Stupid) as a methodological counterpoint to KISS (Keep It Simple, Stupid). Members of the CLC team have already attempted to classify the key epistemological and methodological questions in a social simulation context (Rossiter et al. 2010; Silverman and Bryden 2007). These are tensions that the CLC Project must address when, for example, seeking to combine agent-based and demographic modeling approaches.

\section{EXAMPLES OF CLC MODELS}

Within the context of the CLC Project, the need to combine different modeling approaches to address the issue of health and social care in an ageing society necessitates a multi-pronged approach. By developing an understanding of each of the component disciplines of the project team, then developing models within each and sharing the results, we aim to find points at which these models can be linked. In so doing, we can produce a linked suite of models addressing different levels of the system — with each level being modelled using appropriate methodologies derived from different disciplines, and yet newly informed by elements of the other, companion disciplines in the project.

On the social science side, the development of statistical models begins by defining a research question, and then reviewing relevant datasets and literature in the subject area. For example, in the early stages of the CLC project statistical models of the determinants of disability had been put forward as an essential way to identify the drivers of the need for care. Our statistical models were initially developed using theories from social models of disability, such as Verbrugge and Jette's (1994) disablement process model, which envisages disability as a consequence of the interaction between the environment and an individual's own capability and health. We identified risk factors associated with people's health, capability or disadvantaged residential environment.

We operationalized these concepts using secondary data from the English Longitudinal Study of Ageing (ELSA), a large population study of people aged over 50 in England. ELSA's development was a collaboration between experts from diverse disciplines and the breadth of variables included in the dataset reflect its interdisciplinary origins. However, the interdisciplinary breadth leads to a trade-off. Methodological constraints mean that the measurement of certain concepts is greatly simplified, while other concepts have been omitted from the study altogether. Conversely, the size and breadth of the dataset means that there are still more than 40 variables which could be included in the model. Therefore we had to identify which variables were the key determinants and how the variables were related to each other. Consequently, based on theoretical models we created a series of logistic regression models exploring how different groups of conceptually related variables (e.g., education and occupational social class) interacted and mediated each other.

This kind of rigorous statistical modeling then provides a great deal of useful information for the complexity scientists on the CLC project. We have constructed an agent-based model of the demographics of aging and social care, illustrated in Figure 1. This simulation began as a 'toy' model featuring only the demographic basics: agents of two sexes, with annual age-specific mortality and birth rates, and with the transition from independence to needing care modeled in a similar way to mortality. The aim is not, in the first instance, to parameterize the model with survey data and then use it for prediction, but rather to use it as a test bed for ideas about possible patterns and feedback loops in the overall system. Ongoing 
development of the model involves the inclusion of geographical location (as shown in the figure) and a 'linked lives' approach, i.e., placing each individual within a specific household and family. This allows us to include processes such as marriage and divorce, young adults leaving the family home, etc., and have the individuals themselves keep track of their broader family network. Further down the line, we also plan to incorporate income and employment categories in order to look at both the supply and demand side of social care.

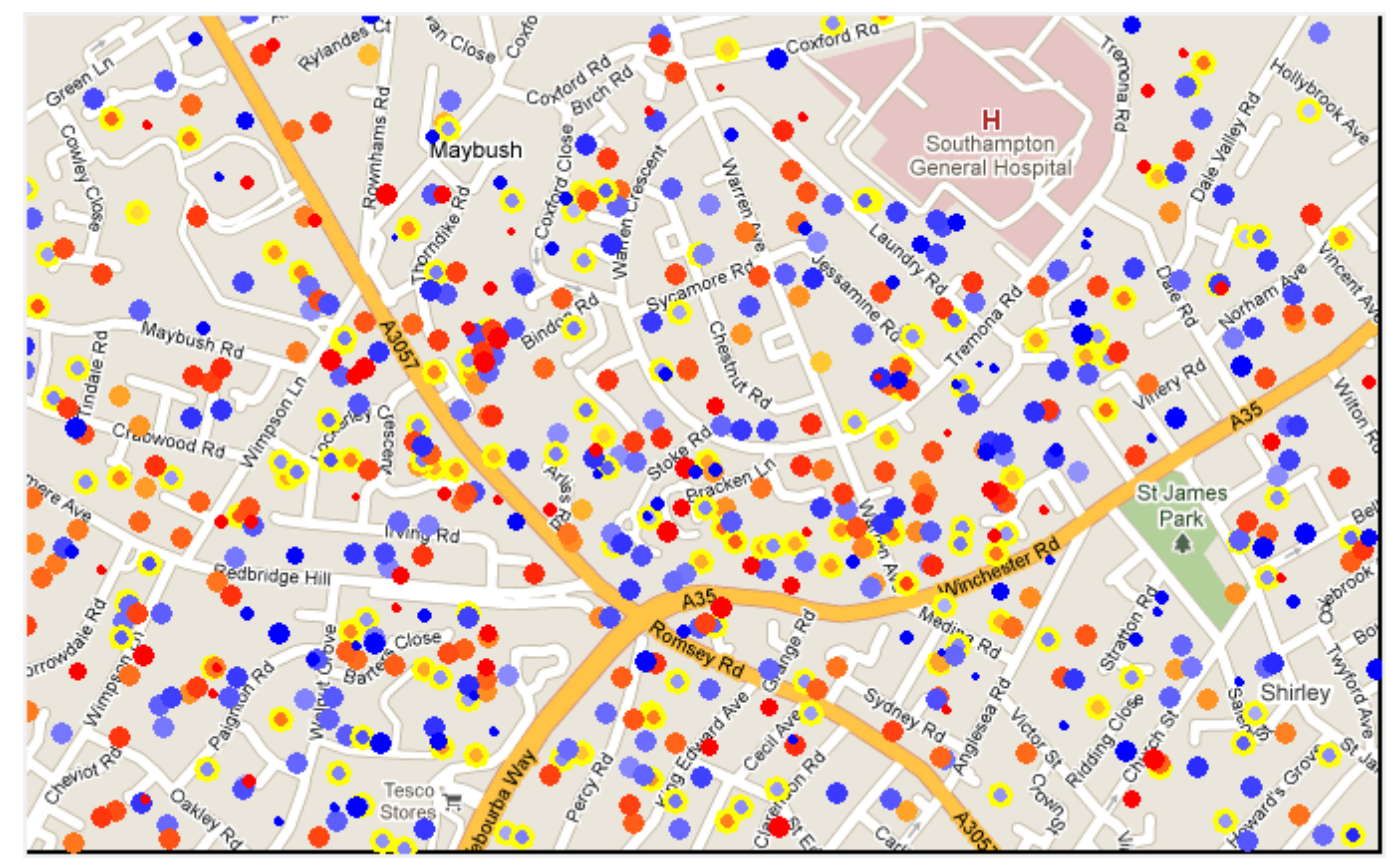

Figure 1. A screenshot from our agent-based model. Red circles are females; blue circles are males; children are smaller circles. The color of the circle fades as the person gets older, and a yellow ring indicates that they have social care needs.

The contrast between our planned agent-based model and existing microsimulation efforts in the social sciences is that we intend to evade the combinatorial explosion in data requirements that is involved in setting every possible transition probability using survey data. Instead, we will develop simple models of the underlying processes (e.g., mortality, employment, decisions about caring for an older relative, etc.) that are initially speculative, but that facilitate holistic validation. In other words, does our multi-process model produce plausible age distributions, family sizes, numbers of older people in social care, etc.? As we become more confident in the model, we can start to ask questions about future scenarios or the effects of potential policies: e.g., looking at the expected prevalence of multi-generational households which would make home-based care more likely, or the expected spatial distance between single elderly people and their nearest family member.

While our statistical models examine trends across UK society in key areas related to issues in health and social care, and while our agent-based model investigates the effects of individual-level behaviors and interactions, the operations research (OR) perspective provides another crucial way to study health and social care at the institutional level. Some early work with Hampshire County Council (hereafter HCC) has allowed us to start work on an OR modeling project which provides a smaller-scale example of what the CLC project will address.

A high-level system dynamics simulation model has been developed in the software VENSIM (see Figure 2). This model was developed in conjunction with the HCC Adult Services Department, and is intended to project the number of people likely to develop care needs over 15 years until 2026. Several 
HCC staff including directors, information managers, data analysts and social workers have been actively engaged in the development of the model. In the model, care needs can be met through: formal care (funded by HCC); informal care (provided by friends, family, etc.); or a combination thereof. When running the model, one can vary the rates at which care needs develop over time, the eligibility criteria for receiving $\mathrm{HCC}$ care, and the probability of receiving informal care.

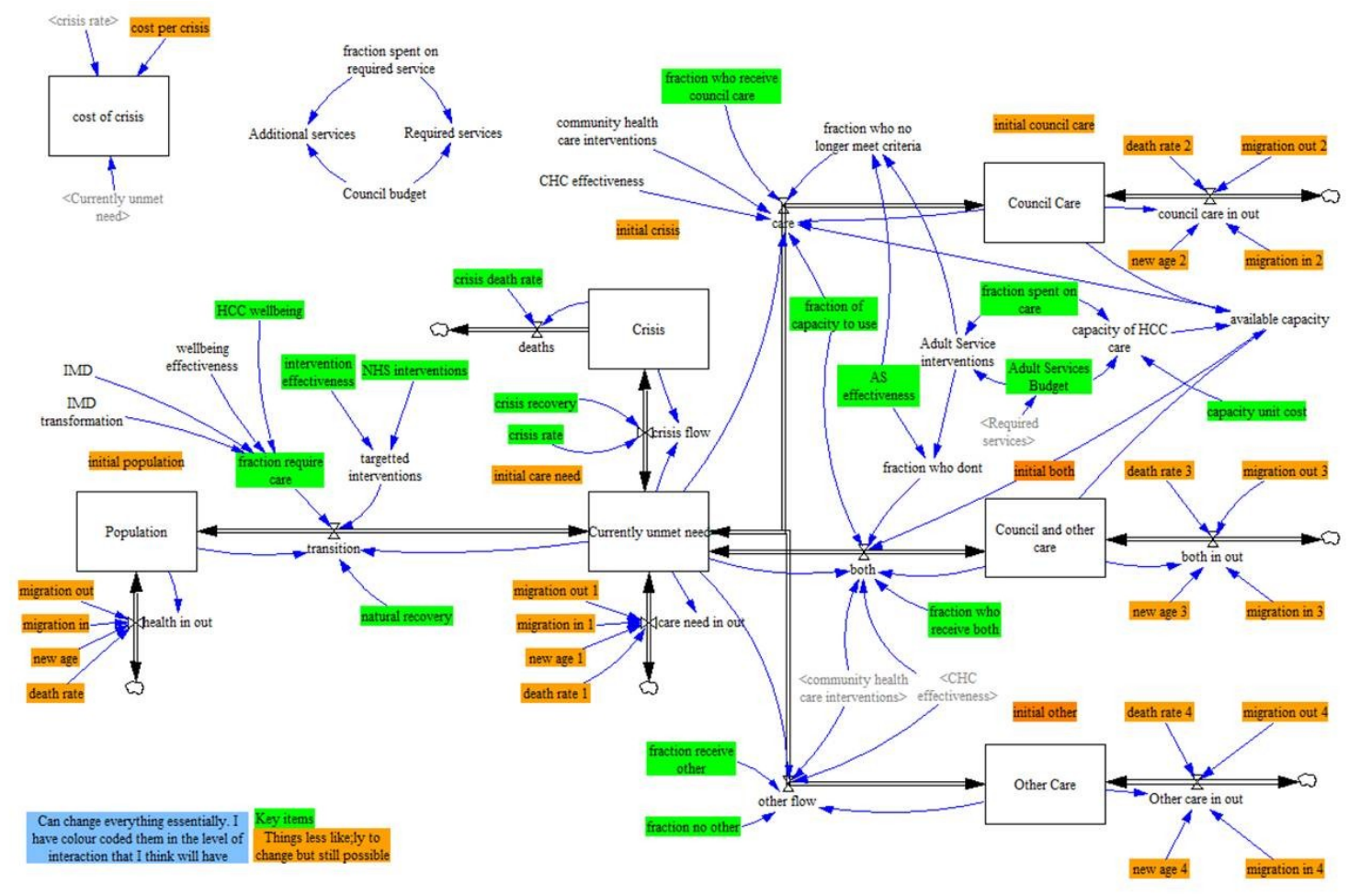

Figure 2: A system dynamics model of a social care system

The model has captured interesting effects, such as the interrelationship of supply and demand which most forecasting models do not adequately take into account. The results also illustrate the complex feedback mechanisms exhibited by the system, and demonstrate the counterintuitive consequences that sometimes result from seemingly well-thought-out interventions. Most importantly for the stakeholders, the model allows them to run data-driven projections, and conduct 'what-if' scenarios involving usergenerated scenarios to examine the effectiveness of other possible intervention strategies.

As the CLC project progresses, these three approaches will be increasingly linked to build a suite of models which represents UK health and social care at multiple levels: population, individual and institutional. Agent-based models at the individual level can be informed by data produced using social statistical models and demographic models, and then linked directly to OR models which simulate the functioning of health and social care institutions. The results from these simulations can then guide the collection and analysis of further social science data. These intersections between disciplines and modeling approaches will allow for new developments at each point of intersection, blurring these disciplinary boundaries and allowing for innovative methods to develop (see Figure 3).

\section{CONCLUSIONS}

This paper has briefly discussed the CLC project, its ambitious interdisciplinary approach, and some of the early models being developed. We are already seeing that the 'softer' aspects of fostering and defining the required interdisciplinary approaches are just as challenging as the 'technical' modeling itself. 
Complexity science is not a well-defined, prescribed method but a loose set of tools and world-views that sometimes challenge the prevailing tenets of the other disciplines involved. This leads to inevitable clashes in terminology and broader ideas on scientific validity and communication. The very simple Figure 3 tries to show that we are moving towards some central cross-over domain of the three main areas.

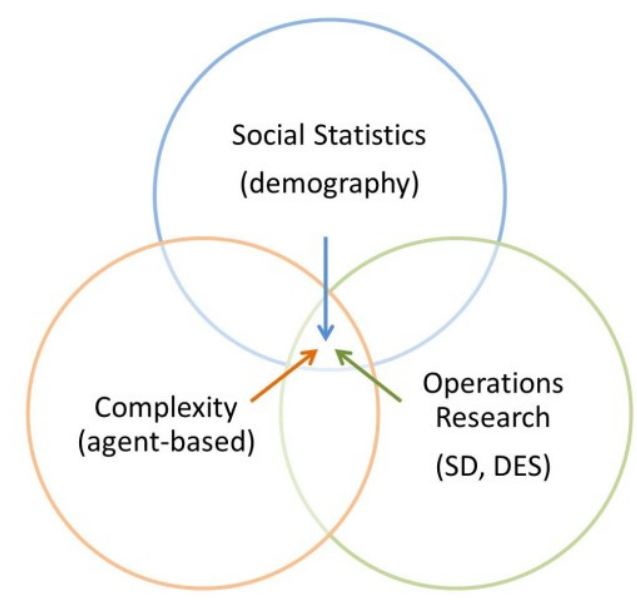

Figure 3: Intersections of disciplines in the CLC

Below, we loosely define the 'standard approach' adopted by each area, and how the complex systems approach might influence it. We must bear in mind that these can verge on caricature, and that there is already research which radically departs from such standards. However, they also serve to reflect the common perception of the disciplines from within the others. Thus, they help define the (often tacitly) entrenched beliefs that we have to overcome. This is why the project management team has placed great emphasis on activities which bring the team together, and in particular, getting the researchers to work in flexible subgroups on several parallel mini-projects.

Social scientists (in this case, demographers and gerontologists) are currently rooted in what can be evidenced in the real world, making use of large databases of survey and census data. These data are then analyzed to produce information which can be used by local authorities or by governments for planning. As a discipline, demography is concerned with predicting the future, based on the past and the present. The statistical methods and models used are traditional, rigorous but rigid, and have limitations which hopefully, will be overcome by the use of innovative approaches from complexity science. Broader than mere probabilistic sensitivity analysis, agent-based modeling allows the exploration of scenarios and structural uncertainty in the models, allowing for the presence of complex, non-linear interactions and feedback effects. More profoundly, the project represents an opportunity to think about modeling in a totally new paradigm where the model structure may be more important than the data. Agent-based modeling opens up the possibility of agents learning from each other through adaptive behavior. Demography will be enriched by a philosophy which allows the exploration and building of theory, leading to models which "involve less computation and more cognition than has generally been applied" (Hajnal 1955).

However, a more common role of agent-based modeling in previous complexity science research has been to explore the qualitative dynamics of system behavior in models which tend to rely less on detailed empirical data for their parameters or calibration. This can give the perception that these are artificial worlds which do not necessarily relate to real-world systems: Maynard Smith famously described the early field of Artificial Life as "basically a fact-free science". The CLC project provides an opportunity to work on high-profile, high-impact, data-rich societal problems where the need to inform policy demands that the modeling methodology is explained and justified in a way which stakeholders can understand. 
Finally, the operations researchers tend to imagine themselves as being between these two extremes of data-driven and theory-driven approaches. However, this self-image may not be accurate. There is mounting evidence that many models reported in the health OR literature have not really been as widely implemented as their academic developers would have liked (Brailsford et al. 2009). Although OR would like to think it always starts with a real-world problem and then seeks a modeling approach with which to tackle this problem, there are many examples in the literature of techniques in search of an application. OR, like complexity science, can learn from demography about being grounded in the real world, working with policy-makers and developing models which have wider significance. By working at the boundaries between these disciplines, both can learn and improve their methods, and develop innovative simulation methodologies together.

These perceptions and tacit assumptions have been evident in the details of debate. The science undertaken by CLC is what science studies scholars call 'Mode 2' science: this aims to not just cross but transcend traditional disciplinary boundaries to reach policy makers and lay audiences (Gibbons et al. 1994). Understandably, issues with sharing theories and tools emerge in such a setting. Concepts are 'founded' differently in different disciplinary domains, leading to the same words having different meaning across disciplinary traditions, and often different meaning from that which we ordinarily ascribe to them (Efstathiou 2009). For example, we have discussed the difference between predictions, projections and forecasts. Even the word 'model' means slightly different things to different audiences.

Throughout the initial project stages, we have already seen some breakthroughs in project members suddenly 'getting' the potential synergies of approach when they have worked through these mental hurdles. This lends us confidence that we are proceeding in the right direction, and that we can bring novelty both within our respective disciplines, and to those uncharted domains between them.

\section{ACKNOWLEDGMENTS}

We gratefully acknowledge the many helpful discussions with the remaining members of the CLC research team not named explicitly as authors on the paper: Seth Bullock, Amos Channon, Maria Evandrou, Jane Falkingham, Rebekah Luff, Olga Maslovskaya, James Raymer, Terry Williams and Rosalind Willis. We also gratefully acknowledge support from the EPSRC under grant EP/H021698/1. Finally, we would like to express our gratitude to Rachel Dittrich and her colleagues at Hampshire County Council.

\section{REFERENCES}

Alho, J. and B. Spencer. 2005. Statistical Demography and Forecasting. Berlin-Heidelberg: Springer. von Bertalanffy, L. 1968. General System Theory: Foundations, Development, Applications. New York: George Braziller.

Bosworth, D., R. Wilson, and D. Baldauf. 2007. "Who does workforce planning well? A rapid review of the workforce review team." Warwick Institute for Employment Research.

Brailsford, S. 2008. "System dynamics: what's in it for healthcare simulation modelers." In Proceedings of the 2008 Winter Simulation Conference, edited by S.J. Mason, R. Hill, L. Moench, and O. Rose. Piscataway, New Jersey: Institute of Electrical and Electronics Engineers.

Brailsford, S., P. Harper, B. Patel and M. Pitt. 2009. "An analysis of the academic literature on simulation and modelling in healthcare." Journal of Simulation 3 (3) part 1: 130-140.

CLC. 2010. "The Care Life Cycle Project." Accessed May 6, 2011. www.southampton.ac.uk/clc/.

CSRW. 2010. "Complexity Science for the Real World." Accessed May 6, 2011. www.csrw.ac.uk/.

Courgeau, D. 2007. Multilevel Synthesis: From the Group to the Individual. Springer Series on Demographic Methods and Population Analysis, vol. 18. Dordrecht: Springer.

Department of Health. 2008a. "Carers at the heart of 21st century families and communities: A caring system on your side, a life of your own." London: TSO.

Department of Health. 2008b. "NHS Next Stage Review: A High Quality Workforce." London: NHS. 
Di Paolo, E., J. Noble and S. Bullock. 2000. "Simulation models as opaque thought experiments". In Proceedings of the Seventh International Conference on Artificial Life, 497-506. Cambridge, MA: MIT Press.

Edmonds, B., and S. Moss. 2005. "From KISS to KIDS: an 'anti-simplistic' modelling approach". In Proceedings of Multi-agent Based Simulation 2004, edited by P. Davidsson et al., 130-144. Springer, Lecture Notes in Artificial Intelligence 3415.

Efstathiou, S. 2009. The Use of 'Race' as a Variable in Biomedical Research. Ph.D. thesis, University of California San Diego.

Epstein, J. M. 2008. "Why model?". Journal of Artificial Societies and Social Simulation, 11(4):12.

Evandrou, M., and J. Falkingham. 2004. "Demographic change in Europe: Implications for family support for older people." In Ageing Without Children, edited by P. Kreager and E. Schroeder-Butterfill, Berhahn Books.

Gibbons, M., C. Limoges, H. Nowotny, S. Schwartzman, P. Scott, and M. Trow. 1994. The new production of knowledge: The dynamics of science and research in contemporary societies. Thousand Oaks, CA, US: Sage Publications, Inc.

Gilbert, N., and K. Troitzsch. 2005. Simulation for the Social Scientist. 2nd ed. Open University Press.

Gleick, J. 1987. Chaos: Making a New Science. Penguin.

Hajnal, J. 1955. "The prospects for population forecasts". Journal of the American Statistical Association, 50(270): 309-322.

Joyce, C., J. McNeil, and J.U. Stoelwinder. 2004. "Time for a new approach to medical workforce planning." Medical Journal of Australia, 180:343-346.

Jóźwiak, J. 1992. Mathematical Models of Population. NIDI Reports, vol. 26. The Hague: NIDI.

Keyfitz, N. 1981. "The limits of population forecasting". Population and Development Review, 7(4): 579593.

Maynard, A. 2006. "Medical workforce planning: Some forecasting challenges". Australian Economic Review, 39:323-329.

Office for National Statistics. 2008. National Population Projections 2006 Based. London, TSO.

Orcutt, G.H. 1957. "A new type of socio economic system." Review of Economics and Statistics, 58:773797.

Rossiter, S., J. Noble, and K.R.W. Bell. 2010. "Social simulations: improving interdisciplinary understanding of scientific positioning and validity." Journal of Artificial Societies and Social Simulation, 13(1): 10 .

Segal, L., and T. Bolton. 2009. "Issues facing the future health care workforce: The importance of demand modeling." Australia and New Zealand Health Policy, 6:12.

Silverman, E., and J. Bryden. 2007. "From artificial societies to new social science theory". In Proceedings of ECAL2007: 9th European Conference on Artifical Life, edited by F. Almeida e Costa, L.M. Rocha, E. Costa, I. Harvey, and A. Coutinho, 645-654. Berlin-Heidelberg: Springer.

Stilwell, B., K. Diallo, P. Zurn, M. Vujicic, O. Adams, and M. Dal Poz. 2004. "Migration of health-care workers from developing countries: Strategic approaches to its management." Bull World Health Organization, 82:595-600.

Verbrugge, L. and A. Jette. 1994. "The disablement process." Social Science \& Medicine, 37(1): 1-14.

Willekens, F. 2005. "Biographic forecasting: bridging the micro-macro gap in population forecasting.". New Zealand Population Review, 31(1): 77-124.

Zinn, S., J. Gampe, J. Himmelspach, and A.M. Uhrmacher. 2009. "MIC-CORE: a tool for microsimulation”. In Proceedings of the 2009 Winter Simulation Conference, edited by M.D. Rossetti, R.R. Hill, B. Johansson, A. Dunkin, and R.G. Ingalls R G, 992-1002. Piscataway, New Jersey: Institute of Electrical and Electronics Engineers. 


\section{AUTHOR BIOGRAPHIES}

SALLY C. BRAILSFORD is Professor of Management Science at the University of Southampton, UK. She received a BSc in Mathematics from the University of London, and MSc and PhD in Operational Research from the University of Southampton. Her research interests include simulation modeling methodologies, system dynamics, health service research and disease modeling, and the modeling of human behavior in healthcare systems. She is chair of the European Working Group on OR Applied to Health Services (ORAHS) and is on the editorial boards of Health Care Management Science, the Journal of modeling in Management, the Journal of Simulation and the Flexible Services \& Manufacturing Journal. Her email address is s.c.brailsford@soton.ac.uk.

ERIC SILVERMAN is a Research Fellow in the School of Social Sciences at the University of Southampton. He received a BA with Honors in Psychology from Pennsylvania State University, and a PhD from the School of Computing at the University of Leeds. After his PhD, he worked as a JSPS Postdoctoral Research Fellow at the University of Tokyo, conducting research in computer simulation and robotics. His work on the CLC Project focuses on the application of complexity science approaches to the social science domain. His email address is e.silverman@soton.ac.uk.

STUART ROSSITER is a Research Fellow in the School of Social Sciences at the University of Southampton. Originally a mathematician, he worked as a software developer and architect for 10 years before an MSc in Multidisciplinary Informations (Leeds University), and is due to graduate with a $\mathrm{PhD}$ in the simulation of electricity generation expansion planning (Strathclyde University). He is interested in general issues of modeling and simulation methodology, particularly in processes, software frameworks and the impacts of complexity-science-based world-views. His email address is s.rossiter@soton.ac.uk.

JAKUB BIJAK is a Lecturer in Demography at the University of Southampton. He holds a PhD from the Warsaw School of Economics, obtained for work on Bayesian migration forecasting. His research interests encompass the applications of quantitative methods in demography, with a special focus on migration, population forecasting, mortality, and demography of conflict. In methodological terms he is interested in the demographic applications of statistical methods (mainly Bayesian), and decision-making under uncertainty. He has just published a book on "Forecasting International Migration in Europe: A Bayesian View" (Springer, 2010). In 2007, Jakub received a Jerzy Z. Holzer Medal for contributions to the Polish demography. His email address is j.bijak@soton.ac.uk.

RICHARD J. SHAW is a research fellow in the School of Social Sciences at the University of Southampton. He received a BSc in Human Sciences and a PhD in Social Epidemiology from University College London. His research interests include health and social inequalities across the life course. His email address is r.j.shaw@soton.ac.uk.

JOE VIANA is a Research Fellow in the School of Social Sciences at the University of Southampton. He received a BSc with Honors in Sport and Health Science with Psychology from the University of Southampton, a MSc with Distinction in Management Sciences from the University of Southampton. He is currently preparing to defend his $\mathrm{PhD}$ thesis which was funded by the Engineering and Physical Sciences Research Council (EPSRC). His PhD advisors are Professor Sally Brailsford and Professor Paul Harper from Cardiff University with clinical advice from Dr Veerakathy Harindra from St Mary's Hospital Portsmouth, UK. His email address is J.Viana@soton.ac.uk.

JASON NOBLE is a Research Fellow in the School of Electronics and Computer Science at Southampton. He received a BA in Psychology from Macquarie University, Sydney, and a DPhil in Cognitive and Computing Sciences from the University of Sussex. He is active in Southampton's Institute for Complex 
Systems Simulation and has a long-standing interest in modeling complex adaptive social and technological systems, with a background spanning AI, philosophy of science, psychology, and statistics. He is an associate editor for the journal Adaptive Behavior and sits on the board of the International Society for Artificial Life. His email address is jn2@ecs.soton.ac.uk.

SOPHIA EFSTATHIOU is a Research Fellow in the School of Humanities at the University of Southampton. She has a joint Honors Masters in Mathematics and Physics from Warwick, an MA in Philosophy and a PhD in Philosophy and Science Studies from the University of California San Diego. Her research and teaching there and at the London School of Economics and Political Science have focused on methodological issues in science and medicine. Her doctoral work on race concepts currently used in biomedicine was funded by US National Science Foundation and White grants. She is independently studying interdisciplinary communication and innovation as it take shapes in CLC work. Her email address is s.efstathiou@soton.ac.uk.

ATHINA VLACHANTONI is a Lecturer in Gerontology at the Centre for Research on Ageing at the University of Southampton. She holds MSc and PhD degrees in social policy from Oxford University and the London School of Economics. Her research interests combine the broad areas of ageing and social policy, focussing on the implications of population ageing for social care provision and the impact of informal care provision on employment patterns and pension rights. Her recent publications include the book "Women, politics and pensions" (Lambert Academic Publishing, 2009) and the journal article "The demographic and socio-economic characteristics of older carers: evidence from the ELSA" (Population Trends, 2010). Her email address is a.vlachantoni@soton.ac.uk. 